\title{
La moralidad de la interrupción del embarazo
}

\author{
MAURICIO CORREA CASANOVA \\ Pontificio Seminario Mayor San Rafael (Chile) \\ maucorca67@gmail.com
}

\begin{abstract}
Resumen
Este artículo examina la moralidad de la interrupción del embarazo por razones médicas a la luz de la propuesta legislativa presentada en el año 2010 por los senadores Matthei y Rossi (Boletín No 7.373-07). Con esta finalidad, el autor distingue entre las patologías que afectan a la madre y aquellas que afectan al feto. A su vez, en el último caso se distinguen dos significados de la inviabilidad fetal: uno restringido y otro amplio. A juicio del autor, cada caso exige un análisis moral diferente cuya solución no es homogénea.
\end{abstract}

Palabras claves: aborto; interrupción del embarazo; inviabilidad fetal; dignidad; anencefalia; trisomía.

\section{The morality of the interruption of pregnancy}

\begin{abstract}
This article examines the morality of the interruption of pregnancy for medical reasons in light of the legislative proposal in 2010 by Senators Matthei and Rossi (Bulletin No. 7373-07). To this end, the author distinguishes between diseases affecting the mother and those that affect the fetus. In turn, in the latter case the two meanings are distinguished fetus was not viable: restricted one and one broad. To the author, each case requires a different moral analysis whose solution is not homogeneous.
\end{abstract}

Key words: abortion, interruption of pregnancy, fetal non-viability, dignity, anencephaly, trisomy.

Doctor en Filosofía (Universidad de Valencia, España). Profesor de Ética y Director académico en el Pontificio Seminario Mayor San Rafael de Valparaíso. Es autor de los libros La tolerancia liberal. Una aproximación a la propuesta ética y política de John Rawls (2013) y Nuevas teorías sobre la tolerancia y el pluralismo (2014). Editor del volumen Documentos del Magisterio Social Pontificio. De León XIII a Benedicto XVI (2013), y co-editor, junto con Pablo Martínez Becerra, del libro La riqueza ética de las profesiones (2010). 


\section{Introducción}

Mi propósito en este artículo consiste en ofrecer una breve reflexión ética sobre la despenalización de la interrupción del embarazo por razones médicas. Con este fin analizaré el proyecto de ley presentado en el parlamento chileno a fines del año 2010 por la entonces senadora Evelyn Matthei (UDI) —ex Ministra del Trabajo durante el gobierno de Sebastián Piñera y candidata presidencial en las recientes elecciones del 2013y el senador Fulvio Rossi (PS) (Boletín N ${ }^{\circ}$ 7.373-07).

En mi análisis distingo entre las patologías que afectan a la madre y aquellas que afectan al feto. En este último caso, a su vez, se distinguen dos sentidos de la inviabilidad fetal: uno restringido y otro amplio. En sentido restringido, se considera aquellos casos, como la anencefalia, en la que existe una certeza científica de que el feto no tiene ninguna expectativa de vida ex utero. Por su parte, en sentido amplio, se analiza aquellas situaciones en que el feto padece una patología grave e incurable que hace prever una corta expectativa de vida. Finalizo mi exposición con una aclaración sobre el alcance y límites de mi propuesta de interpretación.

\section{Contexto legislativo del tema}

En su parte medular el proyecto presentado por Mathei y Rossi plantea lo siguiente: por un lado, en su Art. 1, propone modificar el Art. 345 del Código Penal ${ }^{1}$, añadiendo los siguientes incisos finales:

No se considerará aborto cuando se produzca la muerte del feto como consecuencia de una intervención, tratamiento o administración de algún fármaco que sea indispensable para salvar la vida de la madre, lo que deberá ser certificado por un grupo de tres médicos.

No será punible la interrupción de un embarazo cuando se haya certificado por un grupo de tres médicos la inviabilidad fetal.

\footnotetext{
1 Que dice: «El facultativo que, abusando de su oficio, causare el aborto o cooperare a él, incurrirá respectivamente en las penas señaladas en el artículo 342, aumentadas en un grado». / Art. 342: «El que maliciosamente causare un aborto será castigado: 1. Con la pena de presidio mayor en su grado mínimo, si ejerciere violencia en la persona de la mujer embarazada. 2. Con la de presidio menor en su grado máximo, si, aunque no la ejerza, obrare sin consentimiento de la mujer. 3. Con la de presidio menor en su grado medio, si la mujer consintiere».
} 
Por otro lado, en el Art. 2, propone modificar el Art. 119 del Código Sanitario, que dice: «No podrá ejecutarse ninguna acción cuyo fin sea provocar un aborto», añadiendo luego de la expresión «aborto», la frase «sin perjuicio de lo dispuesto en el Art. 345 del Código Penal».

Esta propuesta legislativa fue acogida en la esfera pública de la sociedad chilena centrando el debate en el llamado aborto terapéutico, o también en el aborto engenésico. Sin embargo, resulta sorprendente constatar que el mencionado proyecto de ley ni siquiera utiliza tales expresiones. Aún más, el término «aborto» aparece sólo una vez, aunque para ser abiertamente descartado y, en cambio, se habla de la interrupción del embarazo.

En mi opinión, esta llamada de atención respecto a los términos exactos en que se expresa la propuesta de ley no debe pasarse por alto en la discusión, ya que plantea el tema de la interrupción del embarazo en situaciones difíciles en que el estado de salud de la madre o del feto suscitan una evaluación ética compleja sobre la intervención médica, la autonomía moral de la madre y el estatuto moral del feto.

\section{No se considerará aborto...}

Matthei y Rossi proponen que no se considere como «aborto» la muerte del feto que se produzca como consecuencia de una intervención, tratamiento o administración de algún fármaco que sea indispensable para salvar la vida de la madre. Aunque en estos términos comúnmente se prefiere hablar de aborto terapéutico, los legisladores proponen abiertamente su eliminación.

De partida, hay que reconocer que la idea del aborto terapéutico es bastante problemática. Incluye, por un lado, un aborto, es decir, la interrupción voluntaria del embarazo destinada a causar la muerte del feto, $y$, por otro lado, una terapia, esto es, un tratamiento cuya acción médica está destinada a sanar o salvar la vida de la madre. A la luz de estos elementos, algunos autores entienden que lo que se considera como terapéntico es la acción del médico que provoca la muerte directa del feto como medio para sanar o salvar a la madre; otros, en cambio, sostienen que lo propiamente terapéutico es la acción médica impostergable que se lleva a cabo sobre la madre con el fin de salvaguardar su salud o su vida, lo que provoca indirectamente la muerte del feto.

La primera definición de lo terapéutico sugiere que el aborto es la misma terapia (o tratamiento) destinada a sanar o salvar la vida de la madre; esto es, la terapia consiste en eliminar una vida humana para salvar 
otra. Esto indica, por cierto, que previamente existe una elección deliberada por parte de la madre, o bien, del médico, que decide dar muerte al feto en gestación con el fin de procurar la salud o la vida de la madre. En este sentido, se da a entender que existe una especie de elección entre dos vidas: la de la madre o la del feto. Este modo de hablar generalmente induce a pensar que una vida tiene mayor valor o dignidad que la otra en ciertos casos o en circunstancias excepcionales, lo cual es ciertamente un error, ya que tanto la vida de la madre como la del feto poseen igual dignidad, motivo por el cual su derecho a la vida exige un mismo respeto incondicional.

Ahora bien, al leer el proyecto de ley, da la impresión que su propuesta se basa en la segunda definición de lo terapéutico, lo cual quiere decir que la interrupción del embarazo se produce como una consecuencia derivada de la aplicación de una terapia que incluso sería válida en caso de que la mujer no estuviera embarazada. A este tenor, creo que se puede considerar como muy acertada en este caso la eliminación de la palabra «aborto» o la expresión «aborto terapéutico». Sin embargo, y desde un punto de vista ético, todavía habría que explicitar ciertas condiciones previas - no indicadas en el proyecto de ley-que contribuyan a entender mejor su eliminación.

La principal de tales condiciones consiste en que la interrupción del embarazo con resultado de muerte para el feto no sea querida ni buscada como fin por la madre o por el médico (es decir, que no coincida con la intención o el fin del agente), sino que efectivamente sea una consecuencia indirecta o un segundo efecto no querido. Esto viene a señalar que la interrupción del embarazo no es un medio o una terapia (tal como sucede con la primera definición indicada más arriba), sino que es una consecuencia no deseada del tratamiento. Esta indicación es éticamente relevante, pues de no mediar la enfermedad y la terapia respectiva destinada a lograr la sanación o salvación de la madre, el embarazo continuaría las etapas de su proceso normal de desarrollo hasta el nacimiento.

Casos clínicos que ilustran lo dicho hasta aquí son el embarazo tubario, las mujeres embarazadas con algún tipo de cáncer, o los cuadros obstétricos severos como preeclampsia (en el Considerando 2 del proyecto de ley se mencionan «la infección ovular y sepsis materna, el síndrome trombocitopénico, la hipertensión portal, algunas enfermedades autoinmunes, etc.»). Al aplicar la terapia respectiva en estos casos la interrupción del embarazo no es en sentido estricto un aborto, ya que la muerte del feto se produce de manera indirecta, no buscada ni deseada, sino que es una consecuencia indeseable de la terapia o del tratamiento. Entre los especialistas, esta situación satisface las condiciones normativas 
implicadas éticamente por el llamado principio del doble efecto que es ampliamente reconocido en bioética (Mangan, 1949; Boyle, 1984)2.

De este modo, podemos concluir que al menos este aspecto de la propuesta legislativa - aunque con las indicaciones mencionadas- posee un elevado consenso médico, ético y jurídico, que lo convierte en un punto de acuerdo mínimo indispensable al iniciar el diálogo sobre otras situaciones más problemáticas. Este consenso también incluye el punto de vista de la moral católica. Tal como sostiene Besio et al. (2008: 10):

...el único caso que entraría en cierto sentido en la acepción propiamente terapéutica, pero que no se aplica en relación con una maniobra abortiva, es la muerte fetal que resulta de la realización de una acción impostergable de carácter estrictamente médico en la madre, es decir, orientada a salvaguardar su salud o su vida, y que trae como consecuencia, no querida ni buscada, la muerte del feto, como sería por ejemplo la extirpación de un tumor uterino. Se trataría de una muerte no provocada directamente ni buscada, sino derivada de una terapia, que es una acción moralmente buena ${ }^{3}$.

Según lo dicho, entonces, en principio no sería necesaria una legislación ad hoc, ya que el Art. 1 del proyecto no representa en sentido estricto ningún ilícito moral ni jurídico; aún más, constituye una práctica médica común en clínicas y hospitales tanto en Chile como en el resto del mun$\mathrm{do}^{4}$. No obstante, a pesar de lo dicho, considero que la legislación propuesta puede ser pertinente en este punto con el fin de distinguir claramente entre la interrupción involuntaria del embarazo por razones médicas o terapéuticas y la interrupción voluntaria del embarazo que es el

Tal como explica Germain Grisez, las condiciones del principio de doble efecto son las siguientes: «Uno puede realizar un acto que tiene dos efectos, uno bueno y otro malo, si se cumplen simultáneamente cuatro condiciones. 1) El acto no debe ser malo en sí mismo, aun prescindiendo de la consideración de los efectos malos. (De este modo no se usa el principio para tratar de los efectos buenos y malos del acto que es un homicidio.) 2) La intención del agente debe ser recta. (Así, si uno busca precisamente la muerte, la acción mortal no puede estar justificada por el principio.) 3) El efecto malo no debe ser el medio para el efecto bueno, porque entonces el mal entra en el ámbito de la propia intención, y el mal no se puede pretender ni siquiera en aras de un buen propósito ulterior. (Así, ciertamente, es un mal matar a alguien para heredar su fortuna.) 4) Debe haber una razón proporcionalmente grave para realizar tal acto, ya que existe una obligación general de evitar el mal hasta donde sea posible. (De este modo uno no puede usar un veneno mortal a los niños para matar roedores en un parque público.)» (Grisez, 1970: 329).

En esta misma línea, véase Besio (1998).

Al respecto, véase el interesante reportaje realizado a Pablo Lavín (2009), Jefe del Servicio de Ginecología y Obstetricia del Hospital Barros Luco. 
resultado de una intervención directa destinada a terminar con la vida del feto. Solo en este último caso hablamos propiamente de un aborto.

\section{El caso de la inviabilidad fetal}

Ahora voy a considerar la cuestión bastante más difícil sobre el estatuto moral de la interrupción del embarazo en el caso de la llamada inviabilidad fetal.

Ante todo, no cabe la menor duda que el diagnóstico prenatal posibilitado por los avances tecnológicos en medicina nos pone ante dramas humanos y dilemas morales que ni siquiera eran previstos en décadas pasadas (Juncosa, 1994). Ser conscientes de esta importante transformación tecnológica y ética, así como de la responsabilidad moral que implica para los afectados, es un primer elemento para llevar adelante una adecuada reflexión moral.

De partida, hay que lamentar que el proyecto de ley no realice ninguna definición sobre qué entiende por «inviabilidad fetal», ya que esto introduce mucha ambigüedad respecto a los casos clínicos en que específicamente debería concentrarse el análisis ético, así como la definición jurídica destinada a la exención penal. De hecho, en el Considerando 4, sólo se habla de «patologías y anomalías genéticas que provocan la inviabilidad fetal, como por ejemplo algunas trisomías, la anencefalia, la pentalogía de Cantrell (sic), etc.». Hablar de «algunas trisomías» es demasiado amplio, ya que alguien podría interpretar que si un neonato posee tres cromosomas 21 en lugar del par habitual, entonces, se puede abortar a quien padece el síndrome de Down (una opción, en todo caso, descartada por los legisladores). De manera semejante, el «etc.» con que finaliza es resbaladizo y fácilmente manipulable.

La idea de la inviabilidad fetal es bastante recurrente en los debates sobre el aborto. En general, sugiere la imposibilidad del feto para tener una vida independiente fuera del útero materno (o sea, la inviabilidad $e x$ utero). Así descrita no hay duda que se requieren demasiadas aclaraciones. Por este motivo, aquí propongo distinguir entre dos sentidos de la inviabilidad fetal: uno restringido y otro amplio. En sentido restringido podemos considerar aquellos casos, como la anencefalia, en que tenemos certeza científica (o sea, médicamente confirmada por el diagnóstico prenatal) de que el feto no tiene ninguna expectativa de vida ex utero. Por su parte, en sentido amplio, podemos entender aquellos casos en que el feto padece una patología grave e incurable que hace prever una corta expectativa de vida, tal como sucede, por ejemplo, con la hidrocefalia grave y progresiva. 
Ahora bien, antes de aplicar esta distinción en el análisis de situaciones médicamente relevantes, es necesario responder a la siguiente pregunta: ¿se justifica la evasión del término «aborto» en el caso de la inviabilidad fetal? Pienso que a diferencia del caso anterior de patologías graves que afectan a la madre embarazada, aquí no podemos evadir el hablar de aborto. En efecto, en sentido estricto se trata de un aborto provocado (aborto procurato) que busca directa e intencionalmente poner fin al embarazo de modo que se produzca la muerte anticipada del feto. Esta acción se justifica por graves razones médicas que afectan al feto. En estos términos, entiendo que los legisladores proponen que la práctica del aborto directo o procurado no sea punible en los casos de inviabilidad fetal, esto es, proponen que ni la mujer ni el médico reciban un castigo o sanción penal (tal como, por el contrario, se encuentra establecido en nuestro ordenamiento jurídico).

Dicho lo anterior, la cuestión que debemos responder es la siguiente: ¿en qué casos de inviabilidad fetal se justifica éticamente la despenalización del aborto procurado? En las páginas que siguen ofrezco mi respuesta a la luz de los dos sentidos de inviabilidad fetal más arriba señalados. Antes de esto, sin embargo, debo aclarar que en mi argumentación dejo de lado la discusión teológica acerca de si los seres humanos tienen almas espirituales o no desde el momento de la concepción o después (George, 2008). Del mismo modo, también evito la ilusoria pretensión de una supuesta «ética científica» anclada en un cientificismo positivista que se pretende totalmente independiente de consideraciones filosóficas, antropológicas o incluso bioéticas (Valenzuela, 2003). Mi modesta opinión es que debemos resolver el desafío planteado a la luz de las mejores evidencias científicas sobre cuándo se puede considerar que estamos ante un nuevo ser humano compatible con lo que un buen razonamiento filosófico considera como una vida humana con valor intrínseco, y a partir de aquí, determinar qué es lo que se le debe moral y jurídicamente a esa vida de modo tal que el Estado asuma las medidas necesarias para garantizar ese derecho moral.

\subsection{La inviabilidad fetal por anencefalia}

La anencefalia es un caso médico límite, ya que se trata del defecto congénito más grave de las anomalías fetales incompatibles con la vida. En efecto, como afirma Cook et al. (2008: 304):

La anencefalia es el más grave de los defectos del tubo neural fetal, resultado de la incapacidad del tubo neural de cerrarse en la base del cráneo durante la tercera o cuarta semana (día 26 a 28) desde la concepción, impi- 
diendo la formación de ciertos huesos craneales que rodean la cabeza. Así, falta parte o todo el cerebro, y el tejido cerebral restante queda expuesto al daño provocado por el líquido amniótico ${ }^{5}$.

Respecto a su diagnóstico, los mismos autores sostienen:

La mortalidad es una consecuencia común de la anencefalia fetal, pero algunos fetos afectados nacen vivos con un tallo cerebral rudimentario. De cualquier manera, debido a la falta de funciones cerebrales, son incapaces de tener consciencia y experimentar dolor, si bien el tronco cerebral puede estar apto para provocar acciones reflejas como la respiración, y ocasionalmente respuestas al sonido y al tacto. Los recién nacidos anencefálicos no son viables ni tratables y su sobrevivencia es usualmente medida en horas más que en días (Cook et al., 2008: 304) ${ }^{6}$.

Junto a su alta incidencia de mortalidad dentro y fuera del útero, hay que considerar, además, que la anencefalia no se presenta aislada, sino que concurren generalmente otras anormalidades congénitas fetales, por ejemplo, a nivel cardiovascular; así también aparece asociada con patologías maternas que pueden poner en riesgo la salud y la vida de la madre (Távara-Orozco, 2006).

Ahora bien, en este escenario lo primero que es necesario definir es el estatuto antropológico del feto anencefálico. Esta es una cuestión decisiva, aunque bien debatida. Al respecto, G. Grisez trata sobre el tema en su monumental obra titulada Abortion: the Myths, the Realities, and the

5 Véase también Shewmon (1988); Hooft (2000: 269-271); Arribalzaga (2001: 355356); Matera (2003: 402); Távara-Orozco (2006: 40 42); Vera (2007: 84); Valenzuela (2008: 304); Besio \& Besio (2008: 784); Obeidi et al. (2010); Lança et al. (2010).

$6 \quad$ Según Hooft (2000: 269-270): «En un alto porcentaje de casos es incompatible con la vida intrauterina en periodos más avanzados del embarazo, y con la extrauterina, absolutamente siempre. La literatura médica indica que el 57\% de los nacidos con vida fallecen dentro de las primeras 24 horas, que sólo el 15\% sobreviven tres días, y que son excepcionales los casos que alcanzan una semana, sin medidas de sostén». Por otra parte, Matera (2003: 403): «En relación al período 'in útero'... En el 65\% de los casos, se produce la muerte del feto en la etapa intrauterina y cuando aparece polihidramnios, se vincula además con un nacimiento prematuro... En cuanto a la etapa postnatal, la mayoría de los casos reportados indican que los bebés murieron en los primeros días después de nacer. En tres amplias series los resultados de supervivencia de más de una semana fueron, en la primera ninguno, en la segunda el 5\% y el $9 \%$ en la tercera». Por último, según Besio \& Besio (2008: 784): «el pronóstico es malo: alrededor del 75\% de estos fetos fallecen in utero. Cuando llegan a nacer, los recién nacidos tienen actividad del tronco encefálico, respiración espontánea y a menudo reflejo de succión, pero se encuentran permanentemente inconscientes. Sin un cuidado intensivo, la mayoría fallece durante los dos primeros días después del nacimiento, y ninguno, según la literatura médica, sobrevive más de algunas semanas». 
Arguments. Al referirse al feto anencefálico este autor habla de un «tipo de monstruo» (type of monster), y formula la siguiente pregunta: «¿Hay que considerar esos monstruos como individuos humanos?». Y seguidamente responde:

Genéticamente, son individuos humanos, aunque el grado de anormalidad hace que nos preguntemos si el espécimen es un ser humano. Un punto de vista posible, si la anormalidad está determinada desde el principio, es que estos individuos deberían ser considerados humanos sólo en su origen. Otro punto de vista posible es que esos monstruos deben considerarse en gran parte del mismo modo que hacemos con un individuo cuya cabeza ha sido volada por un balazo. La consecuencia es similar. Este modo de ver el asunto se ve favorecido por el hecho de que en el embrión anencefálico hay un desarrollo normal hasta un cierto punto, pero por el hecho de que el tubo neural no se cierra conduce a cambios degenerativos (Grisez, 1970: 28).

Nótese que la cuestión planteada no consiste en preguntar si el feto anencéfalo es o no genéticamente un individuo humano en su origen, pues resulta obvio que lo es. Hay un individuo humano vivo en sentido genético desde el momento de la fecundación. Más bien, la cuestión propuesta consiste en preguntar si por razón de su severa malformación degenerativa deberíamos dejar de considerarlo como un ser humano, tal como lo era en su origen. En estos términos, la interrogante formulada es sumamente importante por dos razones: primero, porque nos obliga a establecer la identidad o el estatuto antropológico del feto anencefálico; y segundo, dependiendo del resultado de nuestra indagación anterior, porque a partir de ahí es posible establecer lo que se le debe moralmente. En este punto, el principio guía en el debate se funda en el reconocimiento de que los seres humanos poseen una dignidad o valor intrínseco que es la fuente de obligaciones morales, tal como la del debido respeto a la vida del ser humano desde la fecundación hasta su muerte (Lee \& George, 2008).

En este contexto, Grisez (1970: 30) parece privilegiar la opinión que consiste en comparar al anencefálico con aquel que pierde el cráneo. Sin embargo, a mi parecer, la comparación es desproporcionada, ya que quien ha perdido la mitad del cráneo por causa de una herida hasta que muere, en sentido estricto, es una persona que deja de existir como un organismo humano unitario tras el desenlace de un suceso fatal; mientras que el feto anencefálico, en propiedad, no tiene nada de ese potencial, ya que su grave malformación hace imposible que se desarrolle hasta el punto de lograr una vida humana personal cuyo funcionamiento e inte- 
gración se encuentre dirigido finalmente por un cerebro. ¿Significa, entonces, que el feto anencefálico es un humano sólo en su origen, pero que después ya no lo es?

Otra respuesta a la cuestión formulada la encontramos en E. Sgreccia, quien afirma lo siguiente:

Nos parece que está fuera de discusión el hecho de que el anencefálico es fruto de una fecundación humana, con una forma humana, que desde el momento de la fecundación está teleológicamente dirigido por un principio vital propio. No se debería dudar, por tanto, de que nos encontramos ante un individuo de la especie humana, que hay que respetar como persona del mismo modo que a cualquier otro embrión (Sgreccia, 2000: 702-703).

Obviamente, el feto anencefálico es fruto de una fecundación humana, pero ¿qué significa afirmar que está teleológicamente dirigido por un principio vital propio? La respuesta de Sgreccia no deja de ser enigmática, pues lo que en un embarazo normal constituye un progresivo desarrollo de las estructuras biológicas humanas que configuran a una persona, en cambio, en el caso del feto anencefálico, significa un irreversible proceso de deterioro hasta llegar a la muerte. Este deterioro, a mi entender, no expresa una enfermedad, sino la privación irreversible de la estructura neurológica básica en la constitución de una realidad humana personal (Masiá, 2012). En este sentido, sin el potencial para tener un cerebro se elimina la capacidad normal de todo ser humano para funcionar en su madurez orgánica de manera integral y autodirigida. En consecuencia, el principio vital que dirige teleológicamente el proceso de gestación desde la fecundación queda truncado irremediablemente. No es posible el alumbramiento de una persona.

Aunque ciertamente los datos biológicos no resuelven por sí solos la cuestión moral sobre lo que se debe o no al feto anencefálico, de igual manera estimo que proporciona elementos importantes para el discernimiento que no deben ser desconocidos. Dicho esto, mi propia posición consiste en que la excepcional condición biológica del feto anencefálico introduce una «diferencia moral»(Hooft, 2000: 272-274; Drane, 1992; Diniz, 2005) a partir de la cual resulta éticamente permisible la interrupción del embarazo. En este sentido, pienso que la exigencia moral del respeto a la vida humana, desde la fecundación hasta el momento del nacimiento, no debe desconocer la diferencia moral introducida por el diagnóstico prenatal que detecta el grave daño fetal que es la anencefalia, una privación que imposibilita el potencial para alcanzar las propiedades inherentes que hacen posible en estricto rigor la vida de una persona humana. 
Al tratar este tema algunos hablan de aborto engenésico ${ }^{7}$. Sin embargo, no creo que este sea el caso, ya que es un hecho irrefutable, fundado en el dato científicamente comprobado, que no existe hasta ahora ninguna terapia o tratamiento que permita abordar la anencefalia como una enfermedad, de tal manera que se pueda remediar la carencia de una propiedad tan inherente y fundamental para los seres humanos (Arribalzaga, 2001: 356). Más bien, como he anticipado, se trata de una privación congénita que hace al feto incompatible con la vida ex utero dejándolo sin potencial para alcanzar la condición orgánica unitaria que caracteriza a una persona. En este sentido, opino que es irrazonable pensar que se pueda seleccionar para la mejora de los seres humanos entre fetos que carecen de las propiedades que posibilitan la vida humana. Tampoco, por supuesto, existe discriminación, pues para que una discriminación sea considerada como inmoral o injusta tiene que ser arbitraria, esto es, debe desconocer o negar unilateralmente un bien que en justicia se debe a otro. En este caso, nada se niega al feto anencefálico que él mismo no sea ya incapaz de poseer: la propiedad inherente de un organismo humano capaz de vivir unitariamente la vida. En palabras de Arribalzaga (2001: 355):

Debido a la pérdida de función de los hemisferios cerebrales, no puede existir grado alguno de conciencia al nacer. No puede haber pensamientos, sentimientos, sensaciones, deseos o emociones ni posibilidad de interacción social, memoria, dolor o sufrimiento. Se considera que lo único que puede existir son las funciones del sistema vegetativo autónomo, que, sin embargo, tienen una supervivencia muy corta.

A tenor de lo dicho, tengo que explicitar que mi razonamiento no pretende ofrecer un argumento con la intención de promover el aborto del feto anencefálico, sino que más bien ofrezco un punto de vista que en este caso favorece la primacía moral del derecho de la madre a decidir por ella misma si continúa con su embarazo hasta el nacimiento (Sedano et al., 2008: 790). Ante el caso de la anencefalia, considero que la decisión de continuar hasta el final con el embarazo no constituye un mandato moral universalizable, sino que más bien representa una exigencia supererogatoria que sólo debe imponerse a sí misma la madre embarazada. Tampoco, en consecuencia, debería imponerla el Estado, pues mandar actos catalogados como heroicos no constituye por sí mismo el objeto de la ley.

Por aborto engenésico entiendo una práctica que emplea un estudio de los rasgos genéticos hereditarios en la toma de decisiones reproductivas dirigida a la mejora (o el perfeccionamiento) de la vida humana (Selgelid, 2000; 2004). 


\subsection{La inviabilidad fetal por enfermedad grave}

La inviabilidad fetal por enfermedad grave representa una situación clínica compleja con expectativas de vida diferente a la del feto anencefálico. Como he dicho más arriba, se trata de un caso de inviabilidad fetal en sentido amplio; esto es, se refiere al feto que padece una enfermedad grave e incurable que hace prever una corta expectativa de vida, a pesar de los cuidados médicos proporcionados al nacer. En el Considerando 4 del proyecto de ley se mencionan «algunas trisomías» y la «pentalogía de Cantrell» (sic) (Cantrell et al., 1958; Toyama, 1972).

Ya he manifestado que hablar de «algunas trisomías» resulta demasiado ambiguo y resbaladizo. De partida, hemos de descartar la trisomía 21 o «síndrome de Down» (Down, 1995), que es el único caso de trisomía en la que sobrevive un número significativo de neonatos mucho más allá del año después del nacimiento. Pero podemos pensar en otros ejemplos como la trisomía 18 o «síndrome de Edwards» (Edwards et al., 1960), o la trisomía 13 o "síndrome de Patau» (Patau et al., 1960), que son trastornos genéticos que presentan una combinación de defectos congénitos que incluyen retardo mental grave, acompañados de problemas de salud que comprometen casi todos los sistemas orgánicos del recién nacido. Aunque es difícil hacer predicciones exactas respecto a las expectativas de vida, se puede afirmar que a pesar de ser corta, estos trastornos no son drásticamente fatales en todos los casos; incluso, aunque poco frecuentes, existen algunos informes clínicos con una sobrevida que alcanza hasta la adolescencia.

Al igual que en el caso de anencefalia, el proyecto de ley propone despenalizar la interrupción del embarazo en casos de enfermedad grave incompatible con la vida. En este caso también es mejor hablar de aborto directo o procurado, ya que una vez conocido el grave y delicado estado de salud del feto, se decide directamente causar su muerte anticipada. Las razones que pueden motivar esta difícil decisión son varias y complejas: la corta expectativa de vida del neonato, el sufrimiento provocado por las complicaciones de salud y los tratamientos, así como la deficiente calidad de vida (algo que se experimenta como una vida indigna). En el contexto chileno, además hay que añadir las condiciones deplorables del sistema público de salud -las cuales no facilitan un acceso expedito y de calidad-, la falta de salas cuna adecuadas, o las míseras pensiones para los niños con problemas de salud tan graves. También, y de no menor importancia, hay que mencionar en muchas ocasiones el desamparo de la madre y la familia para cuidar a su hijo en esta situación tan lamentable y trágica. 
No tengo la menor duda que ofrecer una respuesta desde el punto de vista moral a los casos en que el feto padece una enfermedad grave y con un pronóstico de muerte, es muy difícil. Lo es principalmente por la situación humana de extremo dramatismo para todos los afectados. Junto con el sufrimiento de los padres por la muerte inminente del hijo antecede el auténtico calvario por el sufrimiento del neonato y la impotencia de los padres por no poder ayudarlo ${ }^{8}$.

8 En Chile conocemos la polémica moral suscitada por el caso de Karen Espíndola y su hijo Osvaldo ocurrido a fines del año 2008. Con 12 semanas de gestación, el diagnóstico principal de los médicos fue que el feto padecía holopronsencefalia semilobar, una grave anomalía al cerebro. En una emotiva carta hecha pública por los medios de comunicación, Karen afirma: «Sigo pensando que el aborto terapéutico debe ser una opción para las mujeres que sean diagnosticadas con embarazos inviables o en lo que existan nonatos con graves enfermedades, porque finalmente, serán ellos -nuestros niños- los que sufrirán los dolores de sus enfermedades y los horrores de nuestro sistema de salud que acrecienta aún más su dolor. No se trata de ser pro-vida o no. Se trata de creer firmemente en la vida vivida con dignidad». Y respecto al sentido providencial y pedagógico del sufrimiento en la experiencia humana añade: «Muchos me han dicho que todo pasa por algo. Que toda esta experiencia me ayudará para ser más fuerte y un largo etcétera. Y es verdad. Todo esto me ha hecho más fuerte y más conciente de una realidad que antes miraba con distancia. Pero, ¿es válido que niños indefensos sean mirados como instrumentos de Dios o de quien sea, para que otros 'aprendan'? He pensado esto desde hace mucho tiempo y creo que la respuesta es no. No creo que nuestros niños deban sufrir para que otros aprendan de su sufrimiento (es decir, verlos como instrumentos para un fin legítimo). Francamente creo que esa visión es irracional $y$, porque no decirlo, inhumana».

Un testimonio diferente entrega Elisa Walker, quien decidió continuar adelante con su embarazo, a pesar de que el diagnóstico indicaba la inviabilidad del feto por padecer el síndrome de Edwards. En esos momentos se encontraba en Escocia, país en el que está permitido el aborto en estos casos. Según cuenta en una entrevista al diario La Tercera: "Yo nunca había escuchado hablar del síndrome de Edwards y era una pregunta razonable de hacer si me ponía en riesgo a mí. Me dijeron que no, que es la guagua la inviable. Para mí eso fue un factor importante a considerar, no sé cómo hubiéramos reaccionado los dos [con Francisco, su esposo] si el embarazo hubiera puesto en riesgo mi vida. Probablemente, ahí hubiera cambiado todo... no lo sé. En el equipo médico... nunca usaron la palabra abortar. Sí nos decían: 'Piensen bien qué quieren hacer, qué decisiones quieren tomar...' Obviamente, todos sabíamos de qué estábamos hablando. Es parte, yo creo, del respeto que tienen a las parejas que están viviendo esta situación. Tampoco es llegar y hablar de aborto así no más, sincerarlo como tantas alternativas a seguir. Es un tema delicado y, por lo mismo, ellos se preocupan de respetar un espacio de intimidad y de ver cómo la pareja se relaciona con este tema (...). Nunca pensamos en la posibilidad de abortar, pero fue muy importante poder tomar la decisión, porque te da la fuerza para vivir el embarazo, que no es fácil. Con esa decisión, parte un drama también, pues sigues con un embarazo, pero con una guagua de la que desde el principio te tienes que empezar a despedir. Es realmente difícil vivir esto. Creo que en parte lo pudimos vivir bien porque sabíamos que queríamos hacerlo». 
Por otra parte, sin embargo, tampoco hay dudas de que nos encontramos ante una vida humana que no podemos dejar de reconocer como la de una realidad personal en la que permanece siempre su dignidad o valor intrínseco. En este sentido, ni la enfermedad ni el sufrimiento, como realidades inherentes a la vida de todos los seres humanos en cualquiera de sus etapas, es capaz de hacer desaparecer o disminuir esa dignidad. A mi parecer, esta es una diferencia crucial en relación al feto anencefálico, que como proyecto truncado de lo que se preveía como una persona humana, no está enfermo, sino que está privado de manera irreversible de la condición de ser humano, ni tiene conciencia ni experimenta el sufrimiento.

A la luz de lo dicho, pienso que cuando existe un diagnóstico de enfermedad grave que afecta al feto, la posibilidad del aborto es siempre inmoral. Ante todo, porque a pesar de la enfermedad y del previsible sufrimiento, permanece en el feto y más tarde en el neonato la dignidad o valor intrínseco de quien pertenece a la especie humana. Luego, porque no es un derecho de los progenitores el tener hijos sanos ni evitar por cualquier medio el sufrimiento propio ni el de los hijos una vez que éstos inician el camino de la vida. En este sentido, se impone el deber moral de otorgarles un respeto y cuidado acorde con su estatus humano y de modo similar a lo que se hace con cualquier otra persona enferma. Asimismo, y de acuerdo con las circunstancias, deben realizarse todos los procedimientos médicos que aparezcan como éticamente proporcionados a la condición concreta del enfermo y compatibles con su bienestar (evitando, por cierto, el encarnizamiento terapéutico). $\mathrm{Al}$ respecto, los avances tecnológicos en medicina hacen prever una disminución importante del sufrimiento físico del neonato.

En este contexto, considero que es inmoral que el Estado imponga cargas tan exigentes como la de atender a un hijo gravemente enfermo, sin que auxilie al mismo tiempo, tal como lo exige la justicia, a las personas que se encuentran en situación tan dramática. Por este motivo, una vez nacido, el sistema público de salud debe garantizar todo el cuidado médico necesario y proporcionado a su situación de enfermo grave (por ejemplo, estableciendo un programa de cuidados paliativos perinatales). Del mismo modo, la madre y la familia deben recibir la ayuda necesaria de manera que ante esta dramática situación no queden al desamparo y desprovistos del derecho legítimo de promover el bien del hijo gravemente enfermo (por ejemplo, ofreciendo ayuda económica, laboral y un equipo interdisciplinario que acompañe desde el momento del primer 
diagnóstico, entre otras) ${ }^{9}$. En definitiva, pienso que si el Estado chileno promueve legítimamente el derecho a la vida (así lo dice expresamente nuestra Constitución), y en consecuencia exige a los ciudadanos el debido respeto de ese derecho, entonces, también tiene el deber moral impostergable de apoyar a sus ciudadanos para que el cumplimiento de esa obligación se realice en conformidad a la dignidad del neonato, de la madre y de la familia.

\section{Palabras finales}

En el presente artículo he reflexionado desde el punto de vista ético sobre la interrupción del embarazo en situaciones excepcionales que afectan a la vida de la madre o del feto. Con este fin me he propuesto analizar el proyecto de ley formulado por Mathhei y Rossi. Mi conclusión es que con modificaciones este proyecto satisface de manera razonable las condiciones mínimas para lograr un acuerdo entre las visiones enfrentadas en el debate público chileno, al menos en relación a las situaciones analizadas.

Ante esta conclusión pueden surgir dos posibles objeciones. Por un lado, quienes están en contra del derecho a elegir abortar en cualquier situación pueden argumentar diciendo que un posible consenso en torno al caso del feto anencefálico destape una pendiente resbaladiza para aprobar el aborto en otras situaciones, por ejemplo, en el caso de que el embarazo sea el resultado de una violación. Admito que esta posibilidad es factible en la arena de la política contingente, sin embargo, no creo que sea posible sobre la base de los argumentos esgrimidos en este artículo. Esto quiere decir que mi argumentación no sirve para fundamentar un derecho que reconozca en cualquier situación el aborto directamente procurado.

Por otra parte, estoy seguro que mi conclusión no satisface las expectativas de quienes son favorables a reconocer el derecho al aborto porque, según afirman, es un derecho de la madre el decidir sobre su propio embarazo en cualquier situación previsible. A la luz de esta premisa mi conclusión les debe parecer paternalista y, en consecuencia, contraria al principio de autonomía moral (tal como ellos lo interpretan). En este artículo, sin embargo, mi objetivo no ha sido discutir este tipo de argumentos, sino sólo ofrecer una alternativa que considero puede conci-

\footnotetext{
9 Buenos ejemplos, en este sentido, son los trabajos realizados en el Consultorio de Asistencia Perinatal (CAP) del Hospital Clínico de la Universidad de Chile (Valenzuela et al., 2003), así como en la Clínica de la Universidad Católica (Reportaje, 2011).
} 
tar un consenso razonado y estable entre las diferentes visiones morales que están en disputa.

\section{REFERENCIAS}

-Arribalzaga, E. (2001). Trasplante de órganos: ¿puede ser el feto anencefálico un donante potencial? Anales de la Facultad de Medicina, 62 (4): 355-361.

-Besio, M. (1998). Consideraciones éticas sobre el aborto terapéutico. Boletin de la Escuela de Medicina, 27 (1): 34-37.

-Besio, M. y Besio, F. (2008). Estatuto ontológico y ético del feto anencefálico: una perspectiva filosófica. Rev Méd Chile (136), 783-788.

-Besio, M., Chomalí, F., Neira, J. y Vivanco, A. (2008). Aborto "terapéutico". Consideraciones médicas, éticas, jurídicas y del magisterio de la Iglesia católica. Santiago de Chile: Facultad de Medicina. Centro de Bioética. Departamento de Obstetricia y Ginecología. Centro de Estudios Jurídicos Avanzados. Pontificia Universidad Católica de Chile.

-Boyle, J. (1984). The Principle of Double Effect: Good Actions Entangled in Evil. En AAVV, Moral Theology Today: Certitudes and Doubbts (págs. 243-260). The Pope John Center, Sant Louis, Missouri: The Pope John Center.

-Cantrell, J. R., Haller, J. A. \& Ravitsh, M. M. (1958). A syndrome of congenital defects involving the abdominal wall, sternum, diaphragm, pericardium and heart. Surg Gynecol Obstet, 107 (5), 602-614.

-Cook, R. J., Erdman, J. N., Hevia, M. y Dickens, B. M. (2008). Prenatal management of anencephaly. International Journal of Gynecology and Obstetrics, 102 (3), 304-308.

-Diniz, D. (2005). Aborto e inviabilidad fetal: el debate brasileño. Cad. Saúde Pública, 21 (2), 634-639.

-Down, J. L. (1995). Observations on an Ethnic Classification of Idiots (1866). Mental Retardation, 33 (1), 54-56.

-Drane, J. (1992). Anencephaly and interruption of pregnancy: policy proposals for HELs. H.E.C. Forum, 4 (2): 103-119.

-Edwards, J. H., Harnden, D. G., Cameron, A. H., Crosse, V. M. \& Wolf, O. H. (1960). A new trisomic syndrome. The Lancet, 275 (7128), 787-790.

-George, R. P. (2008). Embryo Ethics. Daedalus, 137 (1), 23-35.

-Grisez, G. (1970). Abortion: the Myths, the Realities, and the Arguments. New York and Cleveland: Corpus Books (hay trad. cast. en (1972), Salamanca: Sígue$\mathrm{me})$.

-Hooft, P. (2000). Anencefalia: consideraciones bioéticas y jurídicas. Acta Bioethica, VI (2), 267-282.

-Juncosa, A. (1994). El diagnóstico prenatal: problemática ética. Anuario Filosófico (27), 103-115.

-Lança, M. V., Riveros, A. C., Miglino, M. A. y dos Santos, J. M. (2010). Anencefalia: causas de uma malformaçāo congénita. Rev Neurocienc, 18 (2), 244248.

-Lavín, P. (2009). Reportaje “Doctor en la trinchera”. Paula, agosto, 51-56. 
-Lee, P. \& George, R. P. (2008). The Nature and Basis of Human Dignity. Ratio Juris, 21 (2), 173-193.

-Mangan, J. T. (1949). An historical analysis of the principle of double effect. Theological Studies, 10 (1), 40-61.

-Masiá, J. (2012). Aborto y vida naciente con malformaciones. El País, 2 de agosto.

-Matera, F. (2003). Algunas consideraciones éticas en torno al tema de la anencefalia. Arch Argent Pediatr, 101 (5), 402-405.

-Obeidi, N., Russell, N., Higgins, J. R. y O’Donoghue, K. (2010). The Natural History of Anencephaly. Prenatal Diagnosis, 30 (4), 357-360.

-Patau, K., Smith, D. W., Therman, E., Inhorn, S. L. \& Wagner, H. P. (1960). Multiple congenital anomaly caused by an extra autosome. Lancet, 1 (7128): 790-793.

-Reportaje (2011). Hijos que mueren al nacer. Diálogos (1), 6-11.

-Sedano, M., Sedano, R., Sedano, R., Rodríguez, J. G. y Aedo, S. (2008). Reflexiones sobre la conducta obstétrica en la embarazada con feto anencefálico. Rev Méd Chile, 136 (6), 789-792.

-Selgelid, M. J. (2000). Neugenics. Monash Bioethics Review, 19 (4), 9-33.

-Selgelid, M. J. (2004). ¿El aborto para la prevención de las imperfecciones humanas? Aborto eugenésico, incertidumbres morales y consecuencias sociales. Daimon. Revista de Filosofía (31), 115-130.

-Sgreccia, E. (2000). Manuale di Bioetica (vol. I), Milano: Vita e Pensiero.

-Shewmon, D. A. (1988). Anencephaly: selected medical aspects. The Hastings Center Report, 18 (5), 11-19.

-Távara-Orozco, L. (2006). La anencefalia como indicación médica para interrumpir el embarazo: sustento bibliográfico. Rev Per Ginecol Obstet, 52 (1), 40-45.

-Toyama, W. M. (1972). Combined congenital defects of the anterior abdominal wall, sternum, diaphragm, pericardium, and heart: a case report and review of the syndrome. Pediatrics, 50 (5), 778-792.

-Valenzuela, C. (2003). Ética científica del aborto terapéutico. Rev Méd Chile, 131 (5), 562-568.

-Valenzuela, P. (2008). Problemas bioéticos en torno a la criatura anencefálica. Rev Chil Pediatr, 79 (3), 303-310.

-Valenzuela, P., Ahumada, S., González, A. et al. (2003). Atención perinatal a padres con embarazo de riesgo vital neonatal. Rev Chil Obstetr Ginocol, 68 (3), 214-20.

-Vera, H. (2007). El neonato anencéfalo como donador de órganos. Rev Mex Pediatr, 74 (2), 84-87.

Sumario: Introducción; 1. Contexto legislativo del tema; 2. No se considerará aborto...; 3. El caso de la inviabilidad fetal; 3.1. La inviabilidad fetal por anencefalia; 3.2. La inviabilidad fetal por enfermedad grave; 4. Palabras finales; Referencias. 